Article

\title{
Removal of Organic Micropollutants by Grainy Bentonite-Activated Carbon Adsorbent in a Fixed Bed Column
}

\author{
Gabriela Kamińska \\ Institute of Water and Wastewater Engineering, Silesian University of Technology, 44-100 Gliwice, Poland; \\ gabriela.kaminska@polsl.pl
}

Received: 14 November 2018; Accepted: 4 December 2018; Published: 6 December 2018

\begin{abstract}
Organic micropollutants enter effluent streams and then flow into receiving waters. The volume adversely affects aquatic biota substantially. Therefore, many efforts have been made to develop methods for their elimination. The aim of this study was the removal of organic micropollutants with different properties from WWTP (wastewater treatment plant) effluent in fixed bed columns packed with several combinations of sand, granular activated carbon (GAC), and granular clay-carbonaceous composite. Two types of bentonite-powder activated carbon-based granules (Ben-AC) were prepared within this work, with different calcination temperature. It was found that higher calcination temperature enhanced the surface porosity and adsorption potential versus studied micropollutants due to dihydroxylation resulting in higher chemical activity. Introduction of these granules in the place of GAC in a fixed bed column enhances the removal degree of micropollutants and typical water quality parameters. For example, the reduction degree of color, phosphate, and nitrate concentrations increased from $83 \%, 69 \%$, and $4 \%$ to $95 \%, 83 \%$, and $24 \%$ for column I and II, respectively. The concentration of carbamazepine, octylphenol, nononylphenol, and anthracene was reduced by $75 \%, 83 \%, 72 \%, 99 \%$ in column I, while using column II or III their removal was: $86 \%, 97 \%, 99 \%, 99 \%$, respectively. Independent of the column filling, the removal of carbamazepine was the lowest (75-86\%), while the highest retention was obtained for anthracene (99\%). The study of column performance in the treatment of effluent in time showed that column filled with Ben-AC-400 guaranteed high removal degree in the operating time. The batch adsorption data were better described by both the Langmuir model.
\end{abstract}

Keywords: adsorption; clay-carbonaceous composite; fixed bed column; micropollutants

\section{Introduction}

Micropollutants such as polycyclic aromatic hydrocarbons (PAHs), pharmaceuticals, endocrine disrupting compounds (EDCs), pesticides, and personal care products usually migrate into wastewater after their industrial and domestic application [1-3]. Therefore, they occur in effluent, since their removal by conventional wastewater treatment plant is not complete $[4,5]$. Their low degradation is an effect of high hydrophobicity (PAHs), low solubility in water (EDCs) and toxic character (pesticides) [6,7]. The continuous discharge of these chemicals into the environment significantly affects human health and aquatic biota by causing reproductive, hormonal, and neurobehavioral dysfunction [8]. In this context, the development and implementation of a highly effective method to complete the elimination of micropollutants is a challenge for new wastewater technologies.

Several techniques, including advanced oxidation processes (AOPs) [9-11], membrane filtration [12,13], coagulation [14], and adsorption [15,16] have been used to remove micropollutants from different aqueous media. AOPs and membrane filtration are very effective for the elimination of 
low-biodegradable compounds. However, these methods generate a highly concentrated retentate and produce an undesirable water oxidation by-products [17]. Adsorption is supposed to be the simplest, cheapest, and the most favorable method to reduce micropollutants concentration in wastewater. Adsorption can be conducted in a batch system or in a bed column under continuous conditions. Contrary to batch process, adsorption in a bed column is a simple mode operation. The operation is capable of capturing large loads of micropollutants and guarantees a high degree of removal [18].

Activated carbon, zeolites, clays, graphene oxides, carbon nanotubes, mesoporous silica, biomass wastes, and resin have been found to be very effective adsorbents [19]. As an alternative for well-known adsorbents, grainy clay-carbonaceous composites are considered as highly effective materials for micropollutants removal $[20,21]$. This is due to the much faster adsorption of contaminants by the porous media, the capture of micropollutants by additional and complex mechanisms, and the easy regeneration of exhausted adsorbent [22]. Clay-carbonaceous composites are mainly based on bentonite or kaolin and carbon nanotubes [23,24]; however, composites containing activated carbon, instead of carbon nanotubes, are considered as low-cost adsorbents [25]. Wei et al. developed a granular carbon nanotubes-alumina adsorbent and used it to remove diclofenac and carbamazepine from aqueous solution [23]. Some studies recently have reported using granular clay composite, as adsorbents to remove arsenic and lead [26,27]. Most of these studies were carried out in a batch system [20,24,26,27], which is, on the one hand, very important for the theoretical description of adsorption, and on the other hand, due to practical purposes, very rarely used [28]. In these studies, organic micropollutants were mostly removed from the aqueous solution, where the target adsorbate was the only contaminate in the feed solution. Thus, these studies did not reflect conditions occurring in real water matrices, like surface water or effluent, that contain many different substances affecting the adsorption. Unfavorably, data from the literature presented removal of, at most, several of contaminants with similar properties, like pharmaceuticals, instead of compounds representing different groups of micropollutants [20,23]. In that context, there is an increasing need to study the capture of micropollutants with different properties from environmental samples such as WWTP (wastewater treatment plant) effluent by granular clay-carbonaceous composite, which forms a layer in fixed bed column.

Another novelty of this work is that bentonite-activated carbon-based adsorbent was used in a fixed bed column for the first time. In currently available data from the literature, there are two types of similar studies. The first presents the removal of micropollutants in a fixed bed column packed with conventional materials $[18,29,30]$. The second describes adsorption of micropollutants by grainy composites, however, in batch adsorption studies [20,23,31]. Therefore, this work addresses a distinct lack of discussion between adsorption in fixed bed column and composite adsorbent.

This work aimed to determine the removal efficiency of four micropollutants with different physicochemical properties from WWTP effluent by granular bentonite-activated carbon composite (Ben-AC) and present the first study of this adsorbent in continuous filtration. The experiment was performed in three columns packed with granular activated carbon (GAC), sand and Ben-AC composite to represent an advantage of new granular adsorbent over conventional packing material. Moreover, two different types of granular Ben-AC composites were prepared.

\section{Materials and Methods}

\subsection{Materials}

Powder activated carbon (PAC) Norit SX2 was obtained from Brenntag (Kędzierzyn Koźle, Poland) and used as received. Granular activated carbon WG-12 was obtained from Gryfskand (Hajnówka, Poland). The bentonite was received from Sigma Aldrich (Poznań, Poland). Deionized water was taken directly from a Milli-Q water purification system (Millipore Merck, Warsaw, Poland). Acetonitrile $(\mathrm{ACN})$, methanol $(\mathrm{MeOH})$, dichloromethane $(\mathrm{DMF})$ were purchased from Avantor Performance Materials (Gliwice, Poland). 


\subsection{Micropollutants and Feed Solution}

Four micropollutants, i.e., carbamazepine (CBZ), nonylphenol (NP), octylphenol (OP), and anthracene (ANT) (purity 99\%, Sigma Aldrich, Poznań, Poland) were used as adsorbates. These compounds commonly occur in the aquatic environment and belong to the main groups of environmental and hazardous micropollutants. For example, CBZ is a pharmaceutical, NP and OP are endocrine disruptors, and ANT belongs to PAHs. They show different physical-chemical properties, which are presented in Table 1 . The stock solution of micropollutants was prepared with acetonitrile ( $1 \mathrm{~g} / \mathrm{L})$. Effluent from local WWTP (Gliwice, Poland) was spiked with a sufficient volume of stock solution and used as feed water in this study. The concentration of each chemical in feed water was $0.5 \mathrm{mg} / \mathrm{L}$. The basic physical-chemical characteristic of the effluent is presented in Table 2.

Table 1. Properties of micropollutants.

\begin{tabular}{|c|c|c|c|c|c|}
\hline Compound & Chemical Structure & $\begin{array}{c}\text { Molecular } \\
\text { Mass }^{1}(\mathrm{~g} / \mathrm{mol})\end{array}$ & $\begin{array}{c}\log K_{o w} 1 \\
(-)\end{array}$ & $\begin{array}{c}\text { Solubility in Water } \\
20^{\circ} \mathrm{C}^{1}(\mathrm{mg} / \mathrm{L})\end{array}$ & $\operatorname{pKa}^{1}(-)$ \\
\hline $\begin{array}{l}\text { Carbamazepine } \\
\text { (CBZ) }\end{array}$ & & 236.27 & 2.45 & 17.7 & 13.9 \\
\hline $\begin{array}{l}\text { 4-tert-octylphenol } \\
\text { (OP) }\end{array}$ & & 206.32 & 4.12 & 7 & 10.38 \\
\hline $\begin{array}{l}\text { 4-nonylophenol } \\
\text { (NP) }\end{array}$ & & 220.35 & 5.92 & 5.43 & $10.7-11.7$ \\
\hline Anthracene (ANT) & & 178.55 & 4.45 & 0.043 & - \\
\hline
\end{tabular}

Table 2. Physical-chemical properties of WWTP (wastewater treatment plant) ffluent.

\begin{tabular}{ccccccc}
\hline Parameter & $\begin{array}{c}\text { Color } \\
(\mathrm{mg} \mathrm{Pt} / \mathrm{L})\end{array}$ & $\mathrm{pH}(-)$ & $\begin{array}{c}\mathrm{COD} \\
\left(\mathrm{mg} \mathrm{O}_{2} / \mathrm{L}\right)\end{array}$ & $\begin{array}{c}\text { Phosphate } \\
\left(\mathrm{mg} \mathrm{P}_{\mathbf{P O O}} / \mathrm{L}\right)\end{array}$ & $\begin{array}{c}\text { Nitrate } \\
\left(\mathrm{mg} \mathrm{N}_{\mathrm{NO}} / \mathrm{L}\right)\end{array}$ & $\begin{array}{c}\text { Phenolic Index } \\
(\mathrm{mg} / \mathrm{L})\end{array}$ \\
\hline Value & 112.0 & 7.1 & 7.2 & 2.9 & 7.8 & 0.3 \\
\hline
\end{tabular}

\subsection{Bentonite-Activated Carbon Adsorbent Preparation}

Bentonite-activated carbon adsorbent was prepared from bentonite clay and powder activated carbon SX2 according to the modified method previously presented in Reference [32]. Bentonite and activated carbon were mixed with $1 \%$ nitric acid solution containing surfactant Brij $(4 \mathrm{~g} / \mathrm{L})$ for $30 \mathrm{~min}$. The percentage composition of the mixture for the grainy adsorbent was: $53 \mathrm{wt} \%, 12 \mathrm{wt} \%, 35 \mathrm{wt} \%$ for bentonite, activated carbon, and Brij solution, respectively. Then, from the grease, spherical grains were formed with the diameter of $5 \mathrm{~mm}$. The granules were dried for $30 \mathrm{~min}$ at $80^{\circ} \mathrm{C}$, followed by calcination at $250{ }^{\circ} \mathrm{C}$ (Ben-AC-250) or $400{ }^{\circ} \mathrm{C}$ (Ben-AC-400). Surface morphology of bentonite-activated carbon granules was imaged by a scanning electron microscope (SEM) NOVA NANO SEM 200 (Fei Europe Company, Eindhoven, The Netherlands). 


\subsection{Batch Adsorption Studies}

The adsorption capacity of the GAC, Ben-AC-250, and Ben-AC-400 were determined based on the adsorption isotherms of studied micropollutants. For this purpose, different doses of adsorbents were added into Erlenmayer flasks, and next, $100 \mathrm{~mL}$ of WWTP effluent was spiked with different volumes of the stock solution of micropollutants (concentration of each compound varied from 0.5 to $2 \mathrm{mg} / \mathrm{L}$ ). Additionally, a blank sample (without an adsorbent) was prepared to determine the losses of the compounds in the control sample. The flasks were shaken at $150 \mathrm{rpm}$ until equilibrium was reached (this time was determined in a previous study [32]). After this time, the adsorbent was separated from the effluent using filter paper, and the filtrates were analyzed for micropollutants concentration.

The number of micropollutants adsorbed on the nanotubes was determined by the following equation:

$$
Q_{e}=\frac{\left(C_{0}-C_{e}\right) \times v}{m}
$$

where $Q_{e}$ is the adsorbed amount of the adsorbate $(\mathrm{mg} / \mathrm{g}), C_{0}$ and $C_{e}$ are the initial and equilibrium concentration of the adsorbate $(\mathrm{mg} / \mathrm{L}), m$ is the mass of the sorbent $(\mathrm{g})$, and $v$ is the volume in which the adsorption process was performed (L).

In this study, Langmuir and Freundlich models were used to describe experimental data. The form of the Langmuir and Freundlich isotherms are represented by Equations (2) and (3):

$$
Q_{e}=\frac{a b C_{e}}{1+b C_{e}}
$$

where $a$ is the maximum sorption capacity $(\mathrm{mg} / \mathrm{g})$, and $b$ is the Langmuir constant $(\mathrm{L} / \mathrm{mg})$.

$$
Q_{e}=K_{F} C_{e}^{1 / n}
$$

where $K_{F}$ is the Freundlich constant $((\mathrm{mg} / \mathrm{g})(\mathrm{L} / \mathrm{mg}) \mathrm{n})$, and $n$ is the surface heterogeneity parameter.

The models were fitted to the experimental data using the Microsoft Excel spreadsheet with the Solver add-in. The least-squares method was used to determine the constants of the Freundlich and Langmuir equations.

\subsection{Fixed Bed Column Experiments}

The experimental setup for adsorption study in the fixed-bed columns is shown in Figure 1. It consisted of three glass columns of $15 \mathrm{~mm}$ in diameter by $15 \mathrm{~cm}$ in length. The columns II and III were packed with compositions of sand and Ben-AC granules. Column I was a reference column containing layers of GAC and sand. The details about the loading of the columns are presented in Table 3. Wet-packing of the porous medium was used to minimize layering and air entrapment inside the filing. Columns were mounted vertically, and glass wool was used at the bottom of the column acting as supporting material of the adsorbent bed. After packing the column, deionized water was passed through the column for $2 \mathrm{~h}$, followed by the introduction of the feed water. The flow rate was controlled by a peristaltic pump at $3 \mathrm{~mL} / \mathrm{min}$. A higher flow rate of $6 \mathrm{~mL} / \mathrm{min}$ was also investigated in preliminary studies (data in the Supplementary Materials) and was found to be too high. This was due to the low reduction degree of typical water quality parameters. Many authors suggest that a high flow rate results in short contact time between adsorbate and adsorbent that decreases the amount of uptake [33,34]. The filtrate samples were collected at a regular time interval of $1.5 \mathrm{~h}$ because the exhaustion time $\left(C / C_{0}=90 \%\right)$, determined by the water quality parameter, was around $90 \mathrm{~min}$. The effluent treatment and micropollutants removal were also evaluated in time of the process operation. For this purpose, five filtrate fractions were collected every $20 \mathrm{~min}$. All the experiments were carried out at the room temperature $20 \pm 2{ }^{\circ} \mathrm{C}$. 


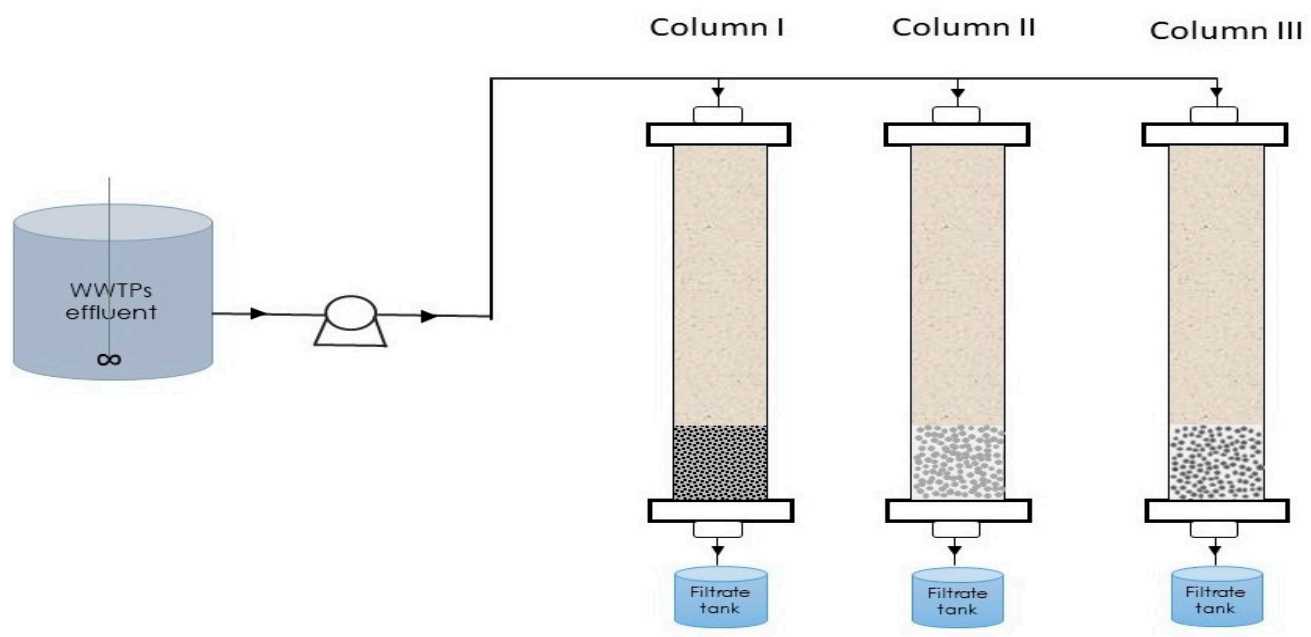

Figure 1. Fixed bed columns setup.

Table 3. Loadings of the columns.

\begin{tabular}{cccc}
\hline Layer Depth & Column I & Column II & Column III \\
\hline $5 \mathrm{~cm}$ & GAC & Ben-AC-250 & Ben-AC-400 \\
$10 \mathrm{~cm}$ & Sand & Sand & Sand \\
\hline
\end{tabular}

\subsection{Water Quality Analysis}

The treatment efficiency of WWTP effluent in fixed bed columns was evaluated by monitoring of typical quality parameters (color, phenolic index, absorbance, nitrate, and phosphate) and measurements of removal of micropollutants. Phenolic index, nitrate, and phosphate concentrations were determined with a Merck test kit numbers: 109713, 100474, 100856, respectively. Color and absorbance $(254 \mathrm{~nm})$ were measured spectrophotometrically. The concentration of micropollutants in the inlet sample and filtrate of the column were measured with HPLC equipped with a chromatography column (Hypersil Gold C18, $5 \mu \mathrm{m}$ particle size, $205 \mathrm{~mm} \times 4.6 \mathrm{~mm}$ ) and the UV-VIS detector. The flow rate of the mobile phase (acetonitrile/deionized water, 95/5, v/v) through the column was $1 \mathrm{~mL} / \mathrm{min}$. HPLC was operated in isocratic elution. Before analysis, analytes were extracted from the samples using solid phase extraction (SPE) (phase C18, $500 \mathrm{mg}, 3 \mathrm{~mL}$, Supelco), according to a previously developed method [35]. Some details of SPE and chromatographic analysis are presented in Table 4.

Table 4. Solid phase extraction (SPE) and chromatographic analysis conditions.

\begin{tabular}{|c|c|c|c|c|c|}
\hline Chemical & Conditioning & Extraction & Elution & $\begin{array}{l}\text { Analysis at } \\
\text { Wavelength }\end{array}$ & $\begin{array}{l}\text { Retention } \\
\text { Time }\end{array}$ \\
\hline ANT & $\begin{array}{c}5 \mathrm{~mL} \mathrm{MeOH} \\
5 \mathrm{~mL} \mathrm{H}_{2} \mathrm{O}\end{array}$ & sample volume: $20 \mathrm{~mL}$ & $3 \mathrm{~mL} \mathrm{DMF}$ & $254 \mathrm{~nm}$ & $4.6 \mathrm{~min}$ \\
\hline OP & $5 \mathrm{~mL} \mathrm{MeOH}$ & extraction speed: 1 & $3 \mathrm{~mL}$ & $220 \mathrm{~nm}$ & $3.5 \mathrm{~min}$ \\
\hline $\mathrm{NP}$ & $5 \mathrm{~mL}$ CAN & $\mathrm{mL} / \mathrm{min}$ & $\mathrm{ACN} / \mathrm{MeOH}$ & $220 \mathrm{~nm}$ & $5.2 \mathrm{~min}$ \\
\hline CBZ & $5 \mathrm{~mL} \mathrm{H}_{2} \mathrm{O}$ & & $60: 40 v / v$ & $284 \mathrm{~nm}$ & $3.2 \mathrm{~min}$ \\
\hline
\end{tabular}

\section{Results and Discussion}

\subsection{Morphology of Bentonite-Activated Carbon Nanocomposite}

The digital photographs of two types of grainy bentonite-activated carbon composites are shown in Figure 2. Ben-AC-250 are brighter than Ben-AC-400. This is related to different calcination temperatures. The higher calcination temperature caused stronger dihydroxylation of bentonite. Structural changes caused by the elimination of hydroxyl groups lead to darkening and an amorphous 
state of matter [36]. The specificity of this state is a thermodynamic imbalance, which affects the high chemical activity of such material. Moreover, the surface morphology of Ben-AC-400 seems to be slightly more heterogeneous, rough, and porous than Ben-AC-250 (Figure 3). It is an effect of higher structure damages due to higher calcination temperatures. As the temperature increases, the activated carbon contained in the bentonite is combusted forming multiple internal pores and channels inside granules. Du et al. suggests that thermal modification is a crucial step in forming a porous structure of grainy clays [37]. Both changes (chemical activity, porous surface) generated by higher calcination temperature of Ben-AC-400 are favorable in the context of adsorption potential.

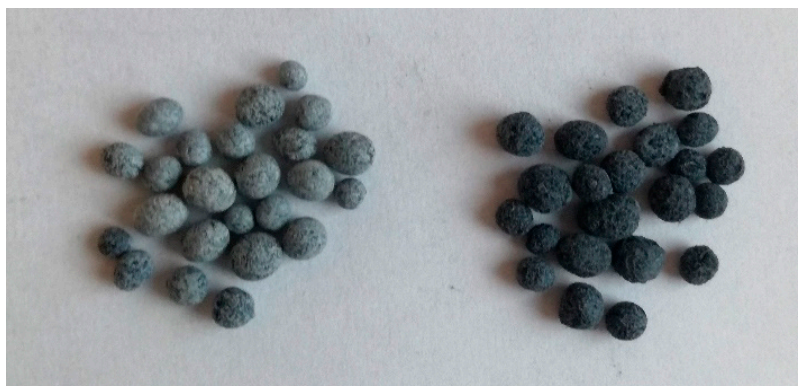

(a)

(b)

Figure 2. Digital photographs of (a) Ben-AC-250; (b) Ben-AC-400.

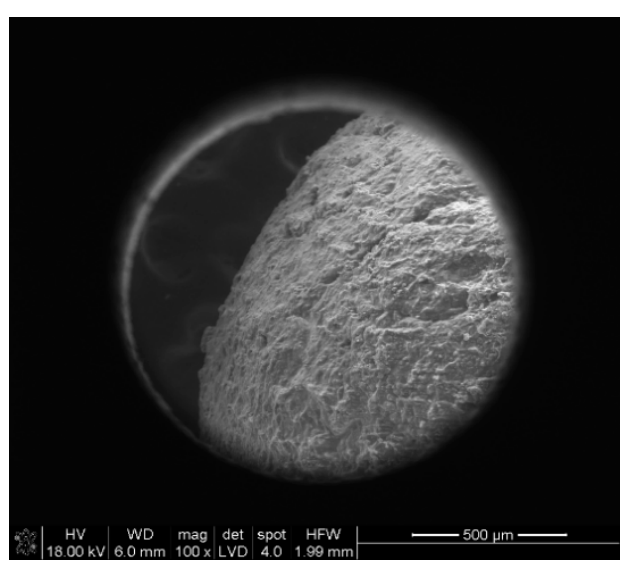

(a)

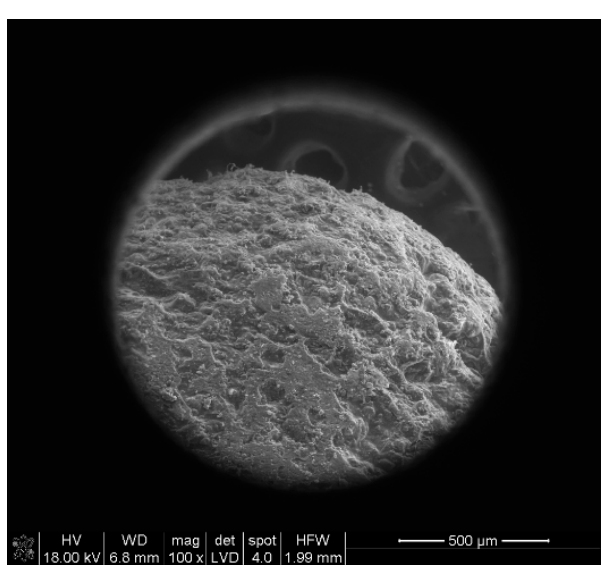

(b)

Figure 3. Scanning electron microscope (SEM) surface images of (a) Ben-AC-250; (b) Ben-AC-400.

\subsection{Adsorption Isotherms}

Figure 4 shows the isotherms of CBZ, OP, NP, and ANT on GAC, Ben-AC-250, and Ben-AC-400. According to the Giles classification, adsorption isotherms for Ben-AC-250 and Ben-AC-400 correspond to L2, while for GAC it is the L1 type. Both suggest a progressive saturation of the adsorbent. In other words, as more sites in the adsorbent are filled it becomes gradually impossible for a bombarding adsorbate molecule to find an empty site available [38]. However, in case of the L1 type isotherms, the curve reaches a distinct asymptotic plateau, which means that adsorbent has a limited adsorption capacity while in the L2 type isotherm there is no plateau meaning that adsorbent does not have a limited adsorption capacity [39].

The Langmuir and Freundlich models were used to describe the experimental data and the relevant parameters derived from these models are presented in Table 5. Based on the R2 value, it was found that the Langmuir model better described the course of adsorption. From the shape of the isotherms, it is evident that the Ben-AC-400 exhibited the greatest sorption capacity. This is also confirmed by the maximum adsorption $a$ and value of the $K_{F}$ constant which were both the highest for Ben-AC-400. 

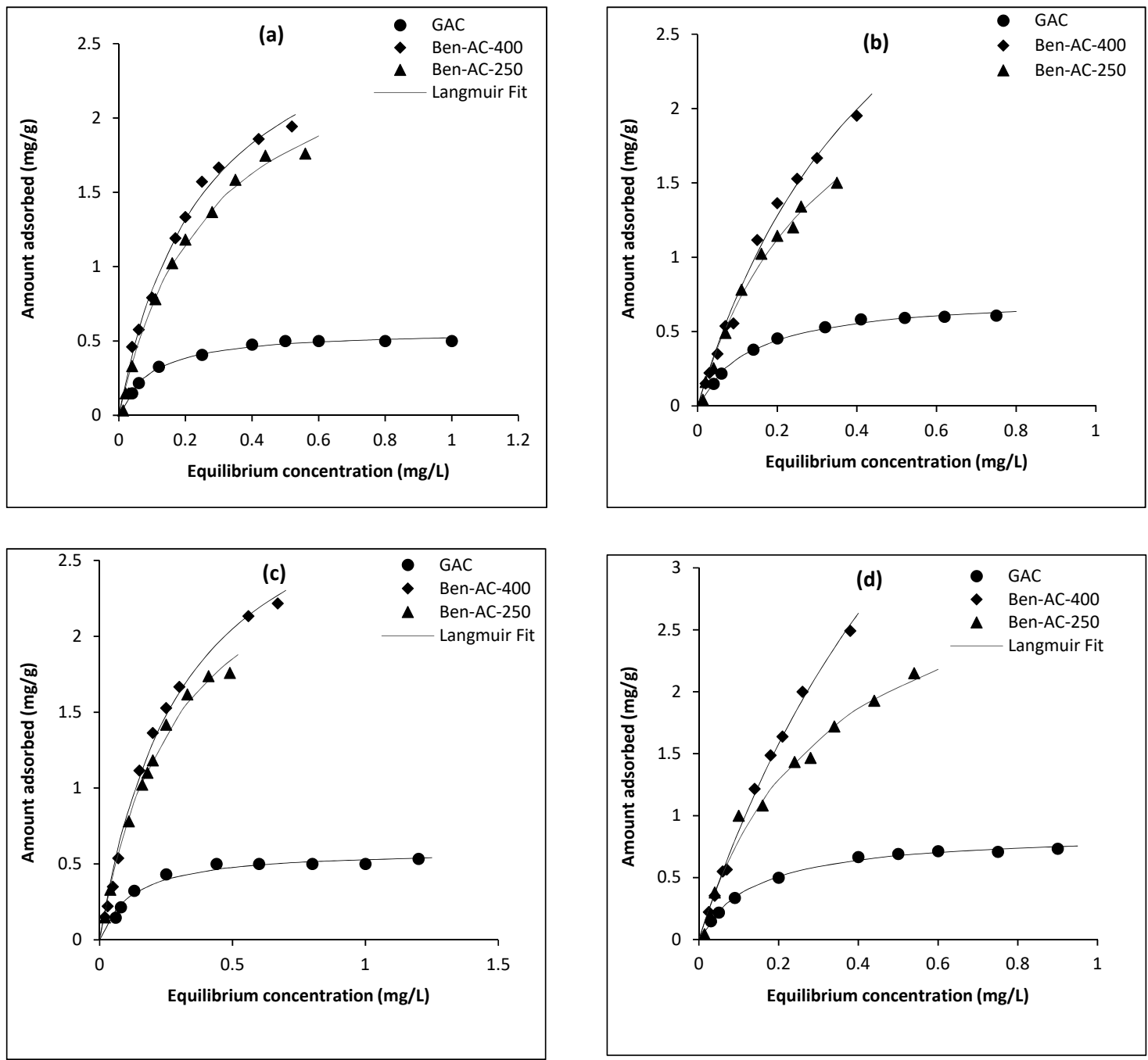

Figure 4. Langmuir adsorption isotherms of micropollutants (a) CBZ; (b) OP; (c) NP; (d) NP on granular activated carbon (GAC), Ben-AC-400 and Ben-AC-250.

Table 5. Parameters of the Freundlich and Langmuir equations and correlation coefficients for the adsorption of micropollutants on granular activated carbon (GAC), Ben-AC-400 and Ben-AC-250.

\begin{tabular}{|c|c|c|c|c|c|c|c|}
\hline \multicolumn{2}{|c|}{ Model } & \multicolumn{3}{|c|}{ Langmuir } & \multicolumn{3}{|c|}{ Freundlich } \\
\hline Adsorbate & Adsorbent & $a(\mathrm{mg} / \mathrm{g})$ & $b(\mathrm{~L} / \mathrm{mg})$ & $\begin{array}{l}R^{2} \\
(-)\end{array}$ & $\begin{array}{c}K_{F}((\mathrm{mg} / \mathrm{g}) \\
\mathrm{L} / \mathrm{mg}) \mathrm{n})\end{array}$ & $\begin{array}{c}n \\
(-)\end{array}$ & $\begin{array}{l}R^{2} \\
(-)\end{array}$ \\
\hline \multirow{3}{*}{$\mathrm{CBZ}$} & Ben-AC-400 & 2.99 & 3.93 & 0.988 & 3.09 & 1.75 & 0.955 \\
\hline & Ben-AC-250 & 2.72 & 3.7 & 0.995 & 2.74 & 1.72 & 0.9695 \\
\hline & GAC & 0.57 & 10.31 & 0.988 & 0.56 & 3.4 & 0.8931 \\
\hline \multirow{3}{*}{$\mathrm{OP}$} & Ben-AC-400 & 4.55 & 1.96 & 0.991 & 4.15 & 1.3 & 0.979 \\
\hline & Ben-AC-250 & 2.97 & 3.02 & 0.994 & 3.45 & 1.4 & 0.98 \\
\hline & GAC & 0.74 & 7.34 & 0.993 & 0.74 & 2.64 & 0.92 \\
\hline \multirow{3}{*}{ NP } & Ben-AC-400 & 3.33 & 3.19 & 0.995 & 2.99 & 1.77 & 0.961 \\
\hline & Ben-AC-250 & 2.94 & 3.4 & 0.994 & 2.92 & 1.7 & 0.970 \\
\hline & GAC & 0.59 & 8.01 & 0.962 & 0.54 & 3.4 & 0.8439 \\
\hline \multirow{3}{*}{ ANT } & Ben-AC-400 & 7.92 & 1.24 & 0.996 & 5.88 & 1.19 & 0.989 \\
\hline & Ben-AC-250 & 3.33 & 3.15 & 0.986 & 3.65 & 1.61 & 0.9739 \\
\hline & GAC & 0.86 & 7.11 & 0.996 & 0.836 & 2.625 & 0.9435 \\
\hline
\end{tabular}


Significant differences were observed in the amount of adsorbed micropollutants. Independently on the adsorbent, the sorption uptake changes were in the following order: ANT $>$ OP $>$ NP $>$ CBZ. To elucidate the factors controlling the adsorption mechanism and sorption affinity of these compounds, we should consider their hydrophobicity, molecular weight, ionic form, and solubility. The higher adsorption of ANT in comparison to the three other adsorbates can be ascribed to the different solubility in water, which is in $\mathrm{mg} / \mathrm{L} 17.7,7.0,5.4,0.04 \mathrm{mg} / \mathrm{L}$ for CBZ, OP, NP, ANT, respectively. The affinity of the adsorbate to sorption is larger when solubility is low [40,41], therefore, it explains the very high sorption uptake of ANT and distinctly lower uptake of CBZ. Molecular weight and log Kow value also affect adsorbed amount. Bigger molecules are hardly adsorbed due to steric hindrance [18]. Thus, adsorption of CBZ, OP, and NP could be limited by molecule size in comparison to ANT. Wang et al. reported that, sorption of polycyclic aromatic hydrocarbons with similar structure increased with an increase in their hydrophobicity. Interestingly, their further studies showed the same tendency for structurally different compounds [42]. This suggests that hydrophobic interactions predominantly regulated sorption of organic compounds [43].

\subsection{Removal Performance in Fixed Bed Columns}

\subsubsection{Effect of Column Filling}

The effect of packing material in columns on the treatment of the effluent and removal of micropollutants is illustrated in Figure 5. Reduction of nitrogen compounds expressed as $\mathrm{N}-\mathrm{NO}_{3}$ (nitrate) was poor in the studied columns, i.e., $3 \%, 18 \%$, and $24 \%$, in column I, II, and III, respectively. Phosphate was reduced by $69 \%$ in column I and by $83 \%$ in column II and III. Bentonite clay is rich in aluminum oxides, which are active in the adsorption of anions such as nitrate and phosphate [44]. When different anions occur in the feed solution, strong competition is observed, and one of them is captured preferentially $[28,45]$. As a result, a strong competitive effect of phosphate on nitrate capture was observed. Gouram-Orimi et al. reported that nitrate uptake in a fixed bed column was limited mostly by phosphate than by the other ions, like bicarbonate or sulfate [46]. According to Schick et al. the adsorption mechanism of these ions is affected by geometry and charge density [47].

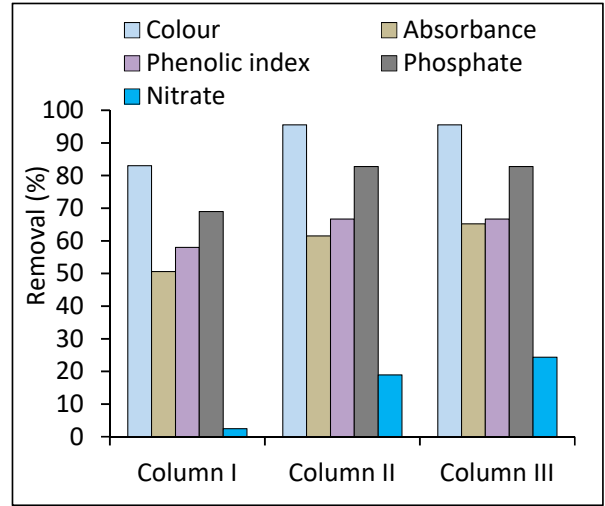

(a)

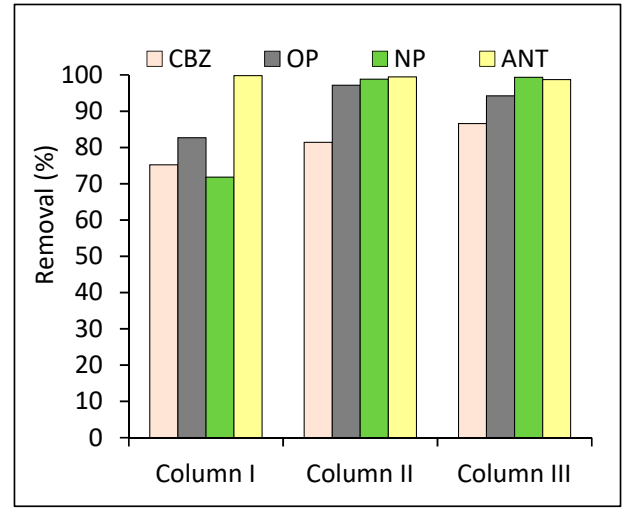

(b)

Figure 5. Impact of column filling on treatment of wastewater: (a) basic quality parameters; (b) micropollutants.

The color was reduced by $83 \%$, while in column II and III, compounds responsible for color were removed almost completely ( $\sim 96 \%)$. Reduction degree of absorbance and phenolic index was also lower in column I than II and III. A similar tendency was found in the removal of micropollutants (Figure 5b). Thus, column II and III were very effective in retaining them. It means Ben-AC composite had better potential to remove pollutants than granular activated carbon. It can be explained by the occurrence of different capture mechanism of the pollutants. It depends on the filling material of 
the filtration bed. As water flows through the porous medium along a tortuous route, the pollution particles are captured by collision, Van der Waals forces, attraction and diffusion. Introduction as a second layer in fixed bed column Ben-AC granules instead of conventional granular activated carbon, enhanced the removal ability of filtration bed, probably due to more intensive adsorption. It is well known that GAC and PAC are heterogeneous and amphoteric materials containing acidic and basic oxygen surface groups. They work as electron donors and Lewis basic sites by donating delocalized $\pi$-electron pairs, respectively. The interaction between adsorbate molecule and these surface groups play a key role in capturing pollutants by GAC and PAC [48]. For example, Yanyan et al. suggest that adsorption of acetaminophen by GAC was an effect of the interaction of carbonyl and oxygen GAC surface groups with the aromatic ring of acetaminophen [49].

Independent of the column filling, the removal of carbamazepine was the lowest (75-86\%), while the highest retention was obtained for anthracene ( $99 \%$ ). It can be explained by differences in solubility of studied micropollutants in water. Chemicals, well soluble in water (like carbamazepine), were poorly removed in the filtration bed, due to the lack of some capture mechanisms that are available for insoluble particles [40,41]. On the other hand, this lowest adsorption of CBZ can be an effect of limited internal transport inside the microporous structure, due to steric hindrance. Sotelo et al. suggested that diclofenac adsorption by activated carbon was limited by steric hindrance of this compound [18]. Meanwhile, the highest removal of anthracene can be explained by its strong hydrophobicity and low molecular mass; thus, it easily penetrated internal microspores and was uptaken by hydrogen bonding, Van der Walls forces, $\pi-\pi$ interaction. According to Yang et al. PAHs with lower molecular weight were better adsorbed by multiwalled carbon nanotubes than PAHs with higher molecular weight [50].

Comparing columns II and III, it was found that slightly better treatment effects were obtained in column III. This difference is connected with higher adsorption potential of Ben-AC-400 due to higher calcination temperature and formation of a more porous structure. Many authors point out that calcination process has a great influence on two important properties of adsorbents, i.e., specific surface area and pore size. They found, the optimum calcination temperature for zeolite, fly ash, $\mathrm{TiO}_{2}$-silica composite to be in the range of $300-600{ }^{\circ} \mathrm{C}$ [51-54]. Sun et al. reported that calcination has a damaging effect on the structure of raw zeolite and directly affects specific surface area, pore volume, and pore size distribution [55].

\subsubsection{Effect of Filtration Time}

Figure 6 presents the removal performance in fixed bed columns in effluent treatment in time (fractions were collected every $20 \mathrm{~min}$ of filtration). Due to the very low reduction level of nitrate $(<5 \%)$, these results were not included. It was found that reduction degree of color, absorbance, phenolic index, and phosphate decreased in time for all fixed bed columns, however, the highest drop of treatment effects were observed for column I filled with sand and GAC. This indicates the superiority of Ben-AC composites over conventional GAC. Among the analyzed water quality parameters, the highest drop of reduction in time was observed for phosphate. It can be associated with too fast flow rate. Ramirez et al. optimized removal of phosphate in fixed bed column at flow rate of $1 \mathrm{~mL} / \mathrm{min}$ [29]. The decrease in the removal of organic quality parameters in fixed bed columns in time can be an effect of clogging and a reduction of porosity of bed filtration.

As shown in Figure 7, removal of micropollutants seems to be relatively stable compared to the rest of the parameters (i.e., color, absorbance, phenolic index, and phosphate). Interestingly, removal of anthracene increased slightly in time for all columns. These micropollutants varied in molecular weight and, thus, particle size. Anthracene has significantly lower molecular weight contrary to the other micropollutants. Probably, decreasing porosity of filtration bed in time was an enhancing factor for removal of anthracene as the effect of a sieve. 

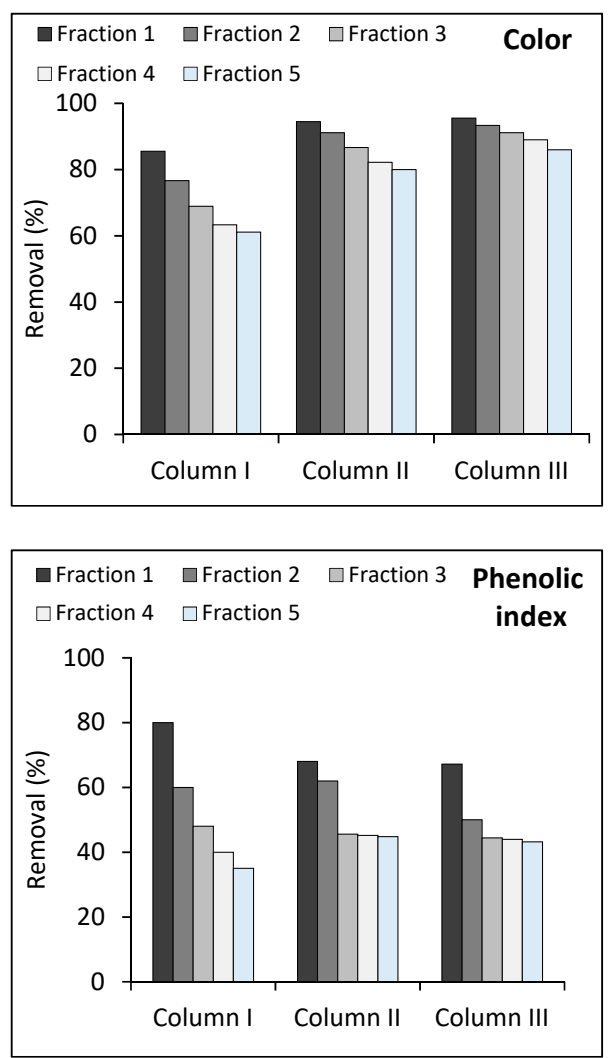
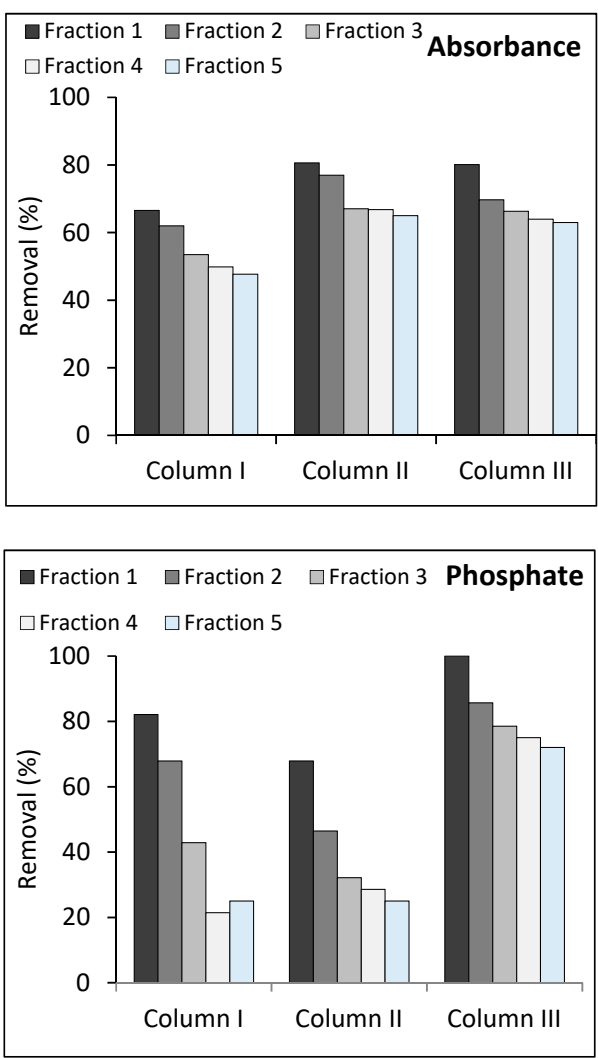

Figure 6. Effluent treatment in fixed bed column in time.
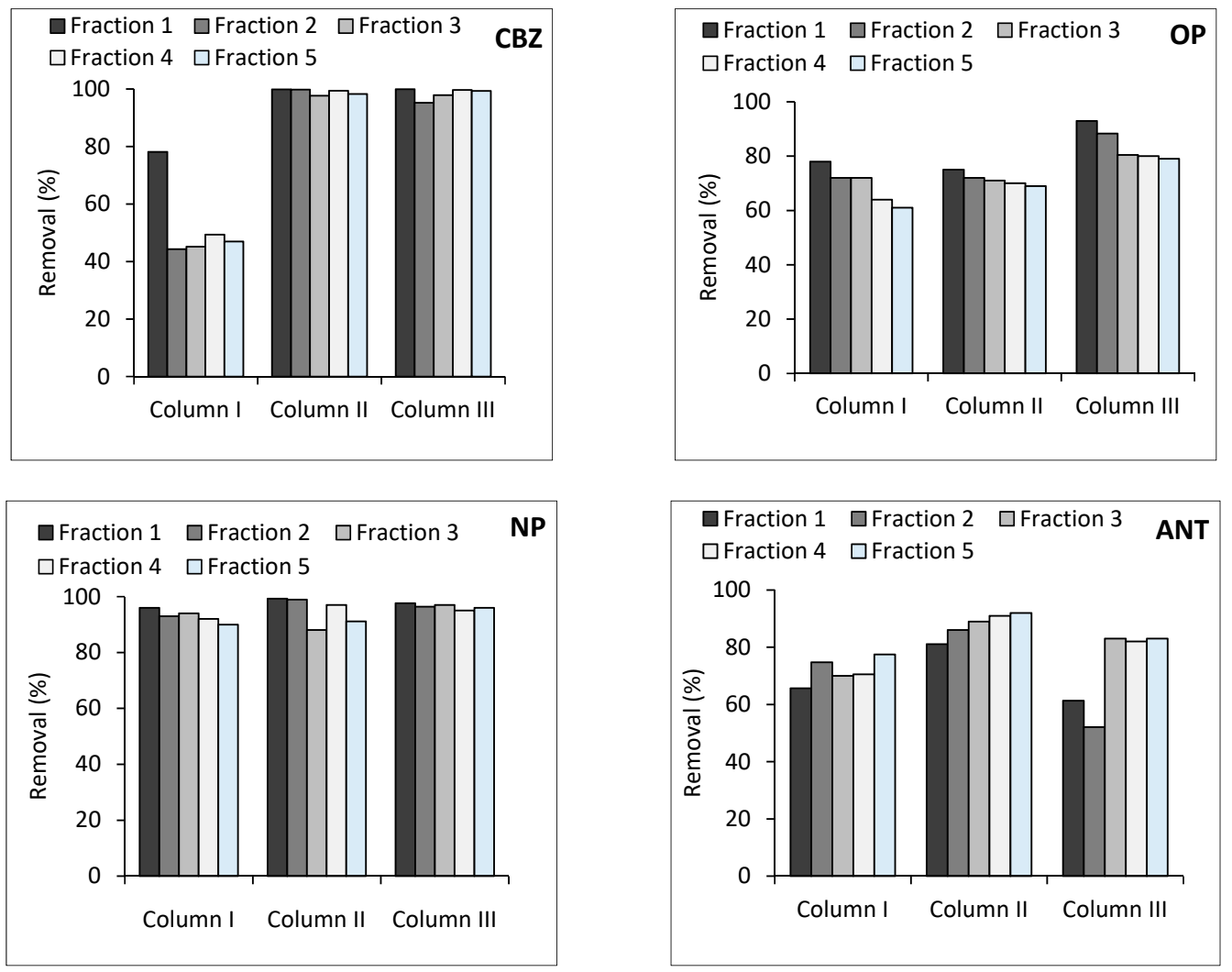

Figure 7. Micropollutants removal in fixed bed column in time. 


\section{Conclusions}

It has been demonstrated that the fixed bed column was a successful method for reduction micropollutants concentration and improvement in typical water quality parameters. Furthermore, replacement of GAC with Ben-AC granules caused the improvement of treatment effects of WWTP effluent, especially in the case of phosphate, nitrate, octylphenol, and nonylphenol. Columns packed with Ben-AC-400 showed slightly better removal performance than Ben-AC-250. It was associated with a higher calcination temperature of Ben-AC-400, which created a more porous structure by stronger structure damages. The higher sorption potential of Ben-AC-400 was also confirmed in batch adsorption studies. Independent of column filling, removal of micropollutants was as follows: The highest removal degree was observed for anthracene and the lowest for carbamazepine. This was due to different physiochemical properties of these micropollutants that determined their capture mechanism by filling material.

It was found over time, that fixed bed columns filled with Ben-AC composite also have a better removal performance. In the case of column I filled with GAC, a significant drop in the reduction degree of CBZ, OP and also phenolic index, phosphate, color, and absorbance was observed. Meanwhile for column II and III reduction degrees of these contaminants were at a relatively high level in the whole time of the experiment. Therefore, these results unequivocally confirm the high potential of clay-carbonaceous composites to remove micropollutants and are a basis for further research, which might, in future, enable the implementation of new and promising adsorbents into fixed bed columns for wastewater treatment technology.

Supplementary Materials: The following are available online at http:/ /www.mdpi.com/2073-4441/10/12/ 1791/s1.

Funding: This research was funded by the Polish Ministry of Science and Higher Education within BK-259/18

Conflicts of Interest: The author declares no conflict of interest.

\section{References}

1. Luo, Y.; Guo, W.; Ngo, H.H.; Nghiem, L.D.; Hai, F.I.; Zhang, J.; Liang, S.; Wang, X.C. A review on the occurrence of micropollutants in the aquatic environment and their fate and removal during wastewater treatment. Sci. Total Environ. 2014, 473-474, 619-641. [CrossRef] [PubMed]

2. K'oreje, K.O.; Kandie, F.J; Vergeynst, L.; Abira, M.A.; Langenhove, H.V.; Okoth, M.; Demeestere, K. Occurrence, fate and removal of pharmaceuticals, personal care products and pesticides in wastewater stabilization ponds and receiving rivers in the Nzoia Basin, Kenya. Sci. Total Environ. 2018, 637-638, 336-348. [CrossRef] [PubMed]

3. Sousa, J.C.G.; Ribeiro, A.R.; Barbosa, M.O.; Pereira, M.F.R.; Silva, A.M.T. A review on environmental monitoring of water organic pollutants identified by EU guidelines. Sci. Total Environ. 2018, 344, 146-162. [CrossRef] [PubMed]

4. Barco-Bonilla, N.; Romero-González, R.; Plaza- Bolaños, P. Systematic study of the contamination of wastewater treatment plant effluents by organic priority compounds in Almeria province. Sci. Total Environ. 2013, 447, 381-389. [CrossRef] [PubMed]

5. Gardner, M.; Comber, S.; Scrimshaw, M.D.; Cartmell, E.; Lester, J.; Ellor, B. The significance of hazardous chemicals in wastewater treatment works effluents. Sci. Total Environ. 2012, 437, 363-372. [CrossRef] [PubMed]

6. Carballa, M.; Fink, G.; Omil, F.; Lema, J.; Ternes, T. Determination of the solid-water distribution coefficient (Kd) for pharmaceuticals, estrogens and musk fragrances in digested sludge. Water Res. 2008, 42, 285-295. [CrossRef] [PubMed]

7. Gavrilescu, M.; Demnerová, K.; Aamand, J.; Agathos, S.; Fava, F. Emerging pollutants in the environment: Present and future challenges in biomonitoring, ecological risks and bioremediation. New Biotechnol. 2015, 32, 147-156. [CrossRef] [PubMed] 
8. Desbiolles, F.; Malleret, L.; Tiliacos, C.; Wong-Wah-Chung, P.; Laffont-Schwob, I. Occurrence and ecotoxicological assessment of pharmaceuticals: Is there a risk for the Mediterranean aquatic environment? Sci. Total Environ. 2018, 639, 1334-1348. [CrossRef] [PubMed]

9. Kudlek, E. Decomposition of contaminants of emerging concern in advanced oxidation processes. Water 2018, 10, 955-973. [CrossRef]

10. Borowska, E.; Bourgin, M.; Hollender, J.; Kienle, C.; McArdell, C.S.; Von Gunten, U. Oxidation of cetirizine, fexofenadine and hydrochlorothiazide during ozonation: Kinetics and formation of transformation product. Water Res. 2016, 94, 350-362. [CrossRef]

11. Borowska, E.; Felis, E.; Kalka, J. Oxidation of benzotriazole and benzothiazole in photochemical processes: Kinetics and formation of transformation products. Chem. Eng. J. 2016, 304, 852-863. [CrossRef]

12. Kamińska, G.; Bohdziewicz, J.; Calvo, J.I.; Prádanos, P.; Palacio, L.; Hernández, A. Fabrication and characterization of polyethersulfone nanocomposite membranes for the removal of endocrine disrupting micropollutants from wastewater. Mechanisms and performance. J. Membr. Sci. 2015, 493, 66-79. [CrossRef]

13. Dudziak, M.; Burdzik-Niemiec, E. Ultrafiltration in the treatment of $17 \beta$-estradiol and bisphenol A containing wastewaters through modified membranes. Przem. Chem. 2017, 1, 202-206. [CrossRef]

14. Cook, M.M.; Symonds, E.M.; Gerber, B.; Hoare, A.; Van Vleet, E.S.; Breitbart, M. Removal of Six Estrogenic Endocrine-Disrupting Compounds (EDCs) from Municipal Wastewater Using Aluminum Electrocoagulation. Water 2016, 8, 128-143. [CrossRef]

15. Kamińska, G.; Bohdziewicz, J. Potential of various materials for adsorption of micropollutants from wastewater. Environ. Prot. Eng. 2016, 42, 161-178. [CrossRef]

16. Bohdziewicz, J.; Kamińska, G. Kinetics and equilibrium of the sorption of bisphenol a by carbon nanotubes from wastewater. Water Sci. Technol. 2013, 68, 1306-1314. [CrossRef] [PubMed]

17. Acero, J.L.; Benitez, J.; Real, F.J.; Teva, F. Micropollutants removal from retentates generated in ultrafiltration and nanofiltration treatments of municipal secondary effluents by means of coagulation, oxidation, and adsorption processes. Chem. Eng. J. 2016, 289, 48-58. [CrossRef]

18. Sotelo, J.L.; Rodriguez, A.; Alvarez, S.; Garcia, J. Removal of caffeine and diclofenac on activated carbon in fixed bed column. Chem. Eng. Res. Des. 2012, 90, 967-974. [CrossRef]

19. Singh, N.B.; Nagpal, G.; Agrawal, S. Water purification by using adsorbents: A Review. Environ. Technol. Innov. 2018, 11, 187-240. [CrossRef]

20. Hiew, B.Y.Z.; Lee, L.Y.; Lai, K.C.; Gan, S.; Thangalazhy-Gopakumar, S.; Pan, G.-T.; Yang, T.C.-K. Adsorptive decontamination of diclofenac by three-dimensional graphene-based adsorbent: Response surface methodology, adsorption equilibrium, kinetic and thermodynamic studies. Environ. Res. 2019, 168, 241-253. [CrossRef]

21. Anastopoulos, I.; Mittal, A.; Usman, M.; Mittal, Y.; Yu, G.; Núñez-Delgadofez, A.; Kornaros, M. A review on halloysite-based adsorbents to remove pollutants in water and wastewater. J. Mol. Liq. 2018, 269, 855-868. [CrossRef]

22. Huang, X.; An, D.; Song, J.; Gao, W.; Shen, Y. Persulfate/electrochemical/ $\mathrm{FeCl}_{2}$ system for the degradation of phenol adsorbed on granular activated carbon and adsorbent regeneration. J. Clean. Prod. 2017, 165, 637-644. [CrossRef]

23. Wei, H.; Deng, S.; Huang, Q.; Nie, Y.; Wang, B.; Huang, J.; Yu, G. Regenerable granular carbon nanotubes/alumina hybrid adsorbents for diclofenac sodium and carbamazepine removal from aqueous solution. Water Res. 2013, 47, 4139-4147. [CrossRef] [PubMed]

24. Shu, Z.; Chen, Y.; Zhou, J.; Li, T.; Sheng, Z.; Tao, C.; Wang, Y. Preparation of halloysite-derived mesoporous silica nanotube with enlarged specific surface area for enhanced dye adsorption. Appl. Clay Sci. 2016, 132-133, 114-121. [CrossRef]

25. Siddiqui, S.I.; Fatima, B.; Tara, N.; Rathi, G.; Chaudhry, S.A. Recent Advances in remediation of synthetic dyes from wastewaters using sustainable and low-cos adsorbents. In The Impact of and Prospects of Green Chemistry for Textile Technology; The textile Institute Book Series; ul-Islam, S., Ed.; Elsevier Science: Amsterdam, The Netherlands, 2019; pp. 471-507.

26. Mo, W.; He, Q.; Su, X.; Ma, S.; Feng, J.; He, Z. Preparation and characterization of a granular bentonite composite adsorbent and its application for $\mathrm{Pb}^{2+}$ adsorption. Appl. Clay Sci. 2018, 159, 68-73. [CrossRef] 
27. Mangwandi, C.; Suhaimi, S.N.A.; Liu, J.T.; Dhenge, R.M.; Albadarin, A.B. Design, production and characterisation of granular adsorbent material for arsenic removal from contaminated wastewater. Chem. Eng. Res. Des. 2016, 110, 70-81. [CrossRef]

28. Golie, W.; Upadhyayula, S. Continuous fixed-bed column study for the removal of nitrate from water using chitosan/alumina composite. J. Water Process Eng. 2016, 12, 58-65. [CrossRef]

29. Ahmed, M.J.; Hameed, B.H. Removal of emerging pharmaceutical contaminants by adsorption in a fixed-bed column: A review. Ecotoxicol. Environ. Saf. 2018, 149, 257-266. [CrossRef]

30. Mohammad, B.; Alighardashi, A.; Sadeghasadi, A. Fixed-bed column and batch reactors performance in removal of diazinon pesticide from aqueous solutions by using walnut shell-modified activated carbon. Environ. Technol. Innov. 2018, 12, 148-159. [CrossRef]

31. Shan, D.; Deng, S.; Zhao, T.; Yu, G.; Winglee, J.; Wiesner, M.R. Preparation of regenerable granular carbon nanotubes by a simple heating-filtration method for efficient removal of typical pharmaceuticals. Chem. Eng. J. 2016, 294, 353-361. [CrossRef]

32. Kamińska, G.; Kuszaj, D.; Bohdziewicz, J.; Dudziak, M.; Kudlek, E. Sorption potential and ability to regenerate granular adsorbent-bentonite-activated carbon. In Technics Problem. Scientific Conference of PhD Students and Young Scientist, Young for Technics 2017; Grabowski, G.P., Krawczyńska-Piechna, A., Warszawska, J.W.P., Eds.; Faculty of Civil, Mechanics and Petrochemistry, Plock Warsaw University of Technology Institute of Civil Engineering: Warsaw, Poland, 2017; pp. 195-204. (In Polish)

33. Liao, P.; Zhan, Z.; Dai, J.; Wu, X.; Zhang, W.; Wang, K.; Yuan, S. Adsorption of tetracycline and chloramphenicol in aqueous solution by bamboo charcoal: A batch and fixed bed column study. Chem. Eng. J. 2013, 228, 496-505. [CrossRef]

34. Meng, M.; Feng, Y.; Zhang, M.; Liu, Y.; Ji, Y.; Wang, J.; Wu, Y.; Yan, Y. Highly efficient adsorption of salicylic acid from aqueous solution by wollastonite-based imprinted adsorbent: A fixed bed column study. Chem. Eng. J. 2013, 225, 331-339. [CrossRef]

35. Bohdziewicz, J.; Dudziak, M.; Kamińska, G.; Kudlek, E. Chromatographic determination and toxicological potential evaluation of selected micropollutants in aquatic environment-Analytical problems. Desalin. Water Treat. 2016, 57, 1361-1369. [CrossRef]

36. Kłosek-Wawrzyn, E.; Małolepszy, J.; Murzyn, P. Sintering behavior of kaolin with calcite. Procedia Eng. 2013, 57, 572-582. [CrossRef]

37. Du, J.; Chadalavada, S.; Naidu, R. Synthesis of porous bentonite organoclay granule and its adsorption of Tributyltin. Appl. Clay Sci. 2017, 148, 131-137. [CrossRef]

38. Giles, C.H.; MacEwan, T.H.; Nakhwa, D.S. Studies in adsorption. Part XI. A system of classification of solution adsorption isotherms, and its use in diagnosis of adsorption mechanisms and in measurements of specific surface areas of solids. J. Chem. Soc. 1960, 10, 3973-3999. [CrossRef]

39. Limousin, G.; Gaudet, J.-P.; Charlet, L.; Szenknect, S.; Barthés, V.; Krimissa, M. Sorption isotherms: A review on physical bases, modeling and measurement. Appl. Geochem. 2007, 22, 249-275. [CrossRef]

40. Nam, S.; Choi, S.; Kim, N.; Her, K.; Zoh, J. Adsorption characteristics of selected hydrophilic and hydrophobic micropollutants in water using activated carbon. J. Hazard. Mater. 2014, 270, 144-152. [CrossRef] [PubMed]

41. Kamińska, G.; Dudziak, M.; Bohdziewicz, J.; Kudlek, E. Single and competitive adsorption of OMPs by carbon nanotubes-Mechanism and fitting models. E3S Web Conf. 2017, 22, 00076. [CrossRef]

42. Wang, X.; Liu, Y.; Tao, S.; Xing, B. Relative importance of multiple mechanisms in sorption of organic compounds by multiwalled carbon nanotubes. Carbon 2010, 48, 3721-3728. [CrossRef]

43. Yang, K.; Zhu, L.Z.; Xing, B.S. Adsorption of polycyclic aromatic hydrocarbons by carbon nanomaterials. Environ. Sci. Technol. 2006, 40, 1855-1861. [CrossRef] [PubMed]

44. Ramirez, A.; Giraldo, S.; García-Nunez, J.; Flóreza, E.; Acelasa, N. Phosphate removal from water using a hybrid material in a fixed-bed column. J. Water Process Eng. 2018, 26, 131-137. [CrossRef]

45. Shang, Y.; Guo, K.; Jiang, P.; Xu, X.; Gao, B. Adsorption of phosphate by the cellulose-based biomaterial and its sustained release of laden phosphate in aqueous solution and soil. Int. J. Biol. Macromol. 2018, 109, 524-534. [CrossRef]

46. Gouran-Orimi, R.; Mirzayi, B.; Nematollahzadeh, A.; Tardast, A. Competitive adsorption of nitrate in fixed-bed column packed with bio-inspired polydopamine coated zeolite. J. Environ. Chem. Eng. 2018, 6, 2232-2240. [CrossRef] 
47. Schick, J.; Caullet, P.; Paillaud, J.L.; Patarin, J.; Mangold-Callarec, C. Nitrate sorption from water on a surfactant-modified zeolite. Fixed-bed column experiments. Microporous Mesoporous Mater. 2011, 142, 549-556. [CrossRef]

48. Bansal, R.C.; Goyal, M. Activated Carbon Adsorption; CRC Taylor ad Francis: Boca Raton, FL, USA, 2005; ISBN 9780824753443.

49. Yanyan, L.; Kurniawan, T.A.; Zhu, M.; Ouyang, T.; Avtar, R.; Othman, M.H.D.; Mohammad, B.T.; Albadarin, A.B. Removal of acetaminophen from synthetic wastewater in a fixed-bed column adsorption using low-cost coconut shell waste pretreated with $\mathrm{NaOH}, \mathrm{HNO}_{3}$, ozone, and/or chitosan. J. Environ. Manag. 2018, 226, 365-376. [CrossRef] [PubMed]

50. Abdullah, N.; Fulazzaky, M.A.; Yong, E.L.; Yuzir, A.; Sallis, P. Assessing the treatment of acetaaminophen-contaminated brewery wastewater by an anaerobic packed-bed reactor. J. Environ. Manag. 2016, 168, 273-279. [CrossRef] [PubMed]

51. Yang, K.; Xing, B. Desorption of polycyclic aromatic hydrocarbons from carbon nanomaterial in waters. Environ. Pollut. 2007, 145, 529-537. [CrossRef] [PubMed]

52. Jeon, E.-K.; Ryu, S.; Park, S.W.; Wang, L.; Tsang, D.C.W.; Baek, K. Enhanced adsorption of arsenic onto alum sludge modified by calcination. J. Clean. Prod. 2018, 176, 54-62. [CrossRef]

53. Elhalil, A.; Farnane, M.; Machrouhi, A.; Mahjoubi, F.Z.; Elmoubarki, R.; Tounsadi, H.; Abdennouri, M.; Barka, N. Effects of molar ratio and calcination temperature on the adsorption performance of $\mathrm{Zn} / \mathrm{Al}$ layered double hydroxide nanoparticles in the removal of pharmaceutical pollutants. J. Sci. Adv. Mater. Devices 2018, 3, 188-195. [CrossRef]

54. Cheng, Y.; Luo, F.; Jiang, Y.; Li, F.; Wei, C. The effect of calcination temperature on the structure and activity of $\mathrm{TiO} 2 / \mathrm{SiO} 2$ composite catalysts derived from titanium sulfate and fly ash acid sludge. Colloid Surf. A 2018, 554, 81-85. [CrossRef]

55. Sun, Q.; Hu, X.; Zheng, S.; Sun, Z.; Liu, S.; Li, H. Influence of calcination temperature on the structural, adsorption and photocatalytic properties of $\mathrm{TiO}_{2}$ nanoparticles supported on natural zeolite. Powder Technol. 2015, 274, 88-97. [CrossRef] 